\title{
The long-term health impacts of repeated flood events
}

\author{
J. Stephenson, M. Vaganay, R. Cameron \& P. Joseph \\ School of the Built Environment and the \\ Built Environment Research Institute, University of Ulster, UK
}

\begin{abstract}
During the past 30 years, floods have resulted in over 200,000 fatalities and affected more than 2.8 billion others worldwide. Flood victims are vulnerable to long-term physical and psychological health effects, which persist for an undefined time period in the aftermath of a flood event. Following a flood event, secondary stressors, which are indirectly related to the event, can potentially prolong and intensify the health impacts on affected individuals and communities. These secondary stressors consist of economic stressors, including loss of income, but also social stressors such as isolation due to prolonged flooding. A significant gap in the research to date is in relation to repeated flooding and its impact on the extent to which individuals are affected by these secondary stressors. This review examined studies focusing on repeated flooding, concentrating on the secondary stressors resulting from repeated flood events. It also considered the awareness, preparedness and resilience of the study populations in order to determine the potential for these communities to be impacted by secondary stressors. This review indicated that both rural and urban communities in developed and developing countries are significantly affected by economic, social and psychological secondary stressors. The majority of communities do have a basic awareness of flood risk; however, many residents do not take flood risk seriously and thus take little preventative action. Community resilience was higher in urban and rural areas in developing countries, but also in rural areas in developed countries. Future work should take into consideration the secondary stressors that affect different communities and how to minimise their impact in order to increase resilience.

Keywords: flooding, repeated flooding, health, secondary stressors, resilience, awareness, preparedness, urban, rural.
\end{abstract}




\section{Introduction}

Flooding has become the most frequent type of major disaster globally within both developing and developed countries [1]. The World Health Organisation concluded that during the past 30 years, flooding resulted in over 200000 fatalities and affected more than 2.8 billion others worldwide [2]. The statistics illustrate that flooding is a worldwide phenomenon and an unquestionable cross border issue.

Flooding poses multiple risks to health and growing evidence worldwide indicates that the health impacts of flooding penetrate a lot deeper than the immediate physical impacts such as injuries and drowning [3]. An increasing recognition is that following extreme events such as floods, secondary stressors, which are indirectly related to the event, can potentially prolong and intensify the health impacts on affected individuals and communities [4]. These secondary stressors take in economic stressors including the impact on property values, but also social stressors such as forced isolation due to a prolonged flood event. Although numerous secondary stressors of extreme events have been identified, there remains a need to establish whether repeated flooding has an impact on the extent to which communities are affected by these stressors and also to investigate if these stressors have similar impacts on different types of communities, such as urban and rural areas.

Therefore the aims of this paper are:

1. To identify studies which have examined the long-term impact of repeated flooding.

2. To summarise and critically review the published literature to date on the secondary stressors impacting urban and rural flooded populations.

3. To establish the awareness, preparedness and level of resilience of communities which have suffered repetitive flooding in order to determine their vulnerability to secondary stressors.

4. To determine the knowledge gaps in the research relating to the longterm health impact of repeated flooding on communities.

\section{Methods}

A literature search using Proquest, Science Direct, Medline and Web of Science was conducted. The search was limited to peer-reviewed articles published in English. Table 1 outlines the search strategy that was used to identify studies to be included in the paper. It included a combination of key words relating to exposure, health outcomes, susceptibility to flooding and the location of the flood event. Studies were eliminated that did not focus on the health impacts of flood events or secondary stressors of flood events. It was also decided to disregard articles which focused solely on immediate impacts of flooding such as mortality, diarrhoeal diseases etc. In addition, papers were excluded that addressed only the health impacts of single flood events. After the search strategy was executed it was decided to discount studies where the sample population did not permanently reside in the area that had been repeatedly flooded i.e. studies on caravan sites. 
The full texts of the remaining articles which met the inclusion criteria were then critically reviewed by the first author, the key findings of which are summarised in this paper.

Table 1: Search strategy used to identify studies for inclusion.

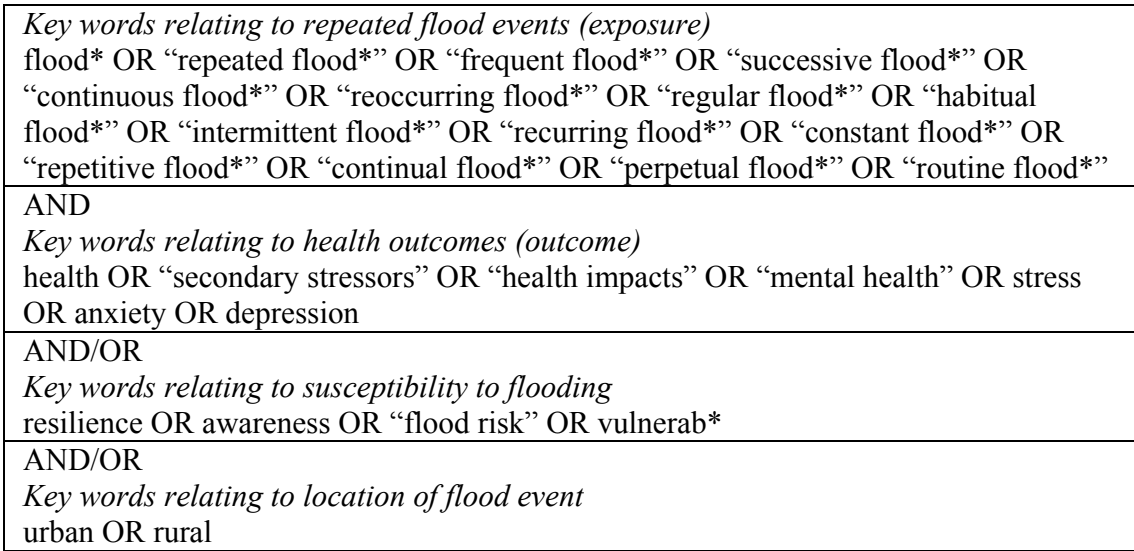

\section{Results and discussion}

The initial search resulted in 4970 potentially relevant references which matched the key words used in the search strategy. Following the application of the inclusion criteria, only 118 articles were reserved for full article review, excluding articles which did not focus on the human health impact of floods. Upon further examination 93 articles were eliminated as not meeting the full criteria, namely repeated flood events. The full texts of the remaining 25 studies were critically analysed by the first author. The studies were divided, where possible, into urban and rural case studies.

Examination of the $25 \mathrm{key}$ articles identified for inclusion in this study revealed that 16 of the studies were in rural locations, 8 were in urban locations and 1 study had both an urban and a rural case study. 12 of the rural studies were in developing countries and 4 in developed countries. 4 of the urban studies were in developing countries and 4 in developed countries. The urban and rural study took place in a developed country.

\subsection{Secondary stressors impacting flood affected populations}

Flood victims are exposed to a traumatic and frustrating sequence of events which can potentially contribute to health implications long after the subsidence of the flood. This is particularly the case for individuals affected by repeated flood events, who are constantly re-exposed to these health implications, often before they have had a chance to recover from a previous flood experience. A significant issue for flood victims is the secondary stressors which come to the forefront in the aftermath of flood events, which can be just as detrimental to health as flood related injuries and diseases. 


\subsubsection{Economic stressors}

3.1.1.1 Loss of income, disruption to livelihoods and debt One of the most significant secondary stressors identified in this study was that flooding affected livelihoods and resulted in substantial loss of income [5-21]. Reasons for loss of income can include: damage to road infrastructure preventing respondents reaching their workplace or dealing with the damage caused to property [5-10, 12, $15,17,19,21,22]$.

Loss of income was a major concern in both urban and rural areas and developed and developing countries. Braun and Aßheuer found that $70 \%$ of households in an urban area in Bangladesh faced a significant decrease in their income following flooding [7]. A rural study in Vietnam established that individuals experienced flooding for two to six months annually, thus resulting in a substantial loss of income [13].

Flooding also posed a risk to traditional livelihoods in rural areas $[9,11,12$, $14,15,20]$. Dun found that the disruption caused to rice farmers in Vietnam by repeated flooding resulted in the decision to migrate as there was no alternative livelihood [14]. In Vietnam seasonal migration often occurs as a means for flood affected families to boost their income $[13,14]$.

Debt was an additional economic stressor identified in this review [13, 14, 16, 18]. Nguyen and James identified that the disruption to income caused by flooding often led poor households to acquire high interest loans [13]. Low socio-economic groups often found it very difficult to repay these loans, leading to further stress and anxiety.

It is important to recognise that business owners are often under as great a strain as homeowners following flood events due to the impact on their livelihood [6, 23]. Hoggart et al. found that business owners faced significant worries regarding flooding as it caused physical damage to merchandise, disrupted transportation of deliveries, prevented customer and employee access to the business and had the potential to cause electricity blackouts [6].

Loss of income was a universal problem for the majority of flood victims in the studies examined by this review. Location and socio-economic status did not have any bearing on its impact, although it was more difficult for individuals from developing countries to recover as they often had little or no savings to assist them post-flood.

3.1.1.2 Damage to property and possessions Damage to property is particularly traumatising for flood victims as they often lose not only valuable assets, but also irreplaceable items of sentimental value [5-10, 12, 15, 17, 19, 21, 22]. However, an additional consequence of damage to property noted in this study was that damage to assets such as vehicles could have far reaching implications as it could prevent travel to work, resulting in loss of income, as well as limiting social interaction $[5,7]$. Furthermore the potential for damage to possessions to occur can affect lifestyle choices, as repeated flood risk can restrict the appliances or furniture that flood victims can realistically purchase [5]. Returning properties to their pre-flood status is very difficult as state compensation is often inadequate and many do not have enough savings to restore dwellings immediately $[15,19]$. 
Damage to property and possessions can be extremely traumatising as flood victims lose both essential items and items that are irreplaceable to them. Due to repeated flooding, individuals may have to go through this stress multiple times. The review shows that damage to property and possessions was also a widespread stressor, suffered in rural and urban areas and developed and developing countries. However, it can be concluded that it has a much more significant impact in developing countries, as individuals do not have the financial resources to replace everything that was lost.

3.1.1.3 Insurance and house prices Following a flood event, the key priority for homeowners is to restore their property to its pre-flood state. However, with the increasing prevalence of flooding, a rising problem is obtaining flood insurance $[17,23,24]$. A UK study by Lamond et al. noted that $13 \%$ of respondents were refused a quote for insurance due to flood risk and 3\% were denied a renewal due to flood risk [24].

In developed countries the increased prevalence of flooding has led to the need for homeowners to invest in flood insurance. Flood insurance is often non-existent in developing countries and flood victims have to use their savings to cover the financial costs. Obtaining insurance for flood risk areas is now very difficult in developed countries and although the majority of homeowners do eventually obtain insurance, the strain on individuals already traumatised by other flooding related stressors should not be underestimated.

\subsubsection{Social stressors}

3.1.2.1 Fear of reoccurrence For individuals with previous flood experience, the stress and anxiety associated with flood memories leaves them fearful of repeated flooding $[5,16,19,21]$. A study in Guyana, South America found that 58\% of respondents acknowledged that they worried every time it rained heavily [21]. Fear of reoccurrence can be a particular problem in developing countries, where lack of formal flood warning systems means households personally monitor signs of flooding, paying particular attention during prolonged rainfall. This on-going stressor can have a significant impact on daily life, straining family relationships, leaving homeowners wary of going on holiday and often prompting individuals to come home early from work when it starts to rain [5]. In developed countries it can often result in obsession with weather forecasts [16].

Fear of reoccurring flooding is evident in this study in both urban and rural areas, but particularly in urban areas in developing countries. Other secondary stressors can contribute to it such as loss of income and damage to property. It is an extremely difficult stressor to alleviate as only a reduction in flood occurrence or migration can overcome it.

3.1.2.2 Migration and displacement Temporary evacuation is a common occurrence during flood events, in relation to preventing mortality and injuries, but also in order to avoid the adverse health impacts associated with living in a flooded or damp home [5, 7-10, 13-15, 17]. Studies in Bangladesh found that 50$95 \%$ of all respondents had to leave their homes during recurrent flood events [7, 
9]. This is particularly difficult for young children and the elderly who may not understand the situation and feel anxious away from normal surroundings and belongings.

Repeated flooding can eventually leave residents with only one option, that of relocation. A study in New Orleans found that $23 \%$ of respondents were considering, trying or actually selling their home [25]. Recurrent damage to property or successive flooding resulting in damage to crops can encourage migration [14]. Migration, although a means of removing exposure to repeated flooding, can be a secondary stressor in itself as displacement from familiar surroundings and severing of ties from family and neighbours can be extremely distressful $[5,17,24]$. In many circumstances, flood victims wish to remain in their homes despite the high flood risk, due to fear of the unknown. A study in the USA found that while 190 households accepted the relocation offer, 47 rejected it [22]. However, often the constant fear of reoccurring flooding can become too stressful, leaving migration as the only alternative.

It is important to recognise that when the decision to migrate is eventually made, the stress does not necessarily come to an end, due to financial issues such as problems with selling homes or higher house prices in non-flood risk areas [5, 15]. A study in Alaska identified that the main obstacle to migration was government funding, as the cost of relocating the village was too high [22]. In addition, home owners are not always offered what they consider the true value of their property, leading to added stress when deciding whether to agree to government resettlement [15]. Property owners who perceived the condition of their property as higher or were attached to their neighbourhood found it more difficult to relocate, however, fear of future flooding made acceptance easier [16]. Dun identified that when government resettlement occurs, households are provided with a five year loan to buy a housing plot; thus resettlement can actually become an economic stressor, causing individuals to go into debt [14].

Temporary evacuation is common in both rural and urban areas. It is unavoidable in both developed and developing countries in order to protect the health of flood victims. However, this study has found that migration is generally a rural issue, as individuals decide to move permanently to urban areas where they feel that flood risk is a lesser concern. It is essential to recognise that while migration and resettlement reduces physical exposure to the health impacts of repeated flooding, it can increase economic and social vulnerabilities; therefore migration can act as both a solution and a stressor.

\subsubsection{Physical and psychological stressors}

3.1.3.1 Long-term malnutrition During flood events, food supplies are often scare, both due to destruction by floods and inability to reach shops or bring in supplies via damaged roads. In order to survive, flood victims often have to reduce the number of meals they consume [7, 9, 12, 26]. Rodriguez-Llanes et al. concluded that children from flooded homes were more likely to be underweight and underdeveloped compared to children from non-flooded homes. This is a particular concern as child malnutrition is associated with underdevelopment, poor school performance and even premature mortality [26]. 
Long-term malnutrition is a key issue in developing countries, particularly in rural areas where it is more difficult for government and voluntary agencies to reach flood victims to provide aid. It is vital for government agencies to do more to assist flood victims in rural communities in developing countries to prevent long-term health problems.

3.1.3.2 Stress, anxiety and depression Repeated flood events place individuals and communities under severe stress and anxiety due to both social and economic reasons [18, 19, 24, 27]. Stress and anxiety can sometimes have a significant impact on human behaviour. Biswas et al. found that $70 \%$ of mothers and $40 \%$ of fathers abused their children during flood events [18]. The possible long-term health effects of abuse at an early age are widely recognised, including a tendency towards eating disorders and depression [18]. It is important to recognise that the extreme stress and anxiety placed on recurrent flood victims has the potential to lead to mental health problems. In a 2013 study on repeated flood events, Wind et $a l$. found that mental health symptoms, such as anxiety and depression were notably higher than other studies on natural disasters, suggesting that repeated events have an even greater influence on mental health [27].

Stress, anxiety and depression due to flooding were identified in both urban and rural studies in this review. Individuals from developing countries are particularly susceptible as they have limited resources to recover from flooding. Stress, anxiety and depression generally occur as a result of other secondary stressors such as damage to property. It is therefore crucial to acquire a greater knowledge of the impact of flood related secondary stressors to minimise the mental health impacts of recurrent flooding.

3.1.3.3 Isolation Recurrent flood events can prevent individuals commuting to work and school and can often result in families or individuals being isolated for significant periods until the flood waters recede $[8,19]$. Isolation can contribute to mental health conditions as it can cause stress and anxiety to escalate.

The review indicated that this is a problem in both urban and rural areas; in rural areas due to the remote location, while in urban areas flood victims may be unable to leave their homes until the waters recede.

\subsection{Awareness and preparedness for flood events}

It is essential to understand that awareness of and preparedness for flood events are completely separate concepts. In many cases individuals are fully aware of the flood risk, but do not take action, despite previous flood history. In this review, 16 out of the 25 studies considered how aware populations were regarding the risk of repeated flooding. In all of those 16 studies homeowners and business owners were aware at least to some extent of flood risk. However, lack of awareness can be a significant problem in some developing countries due to issues such as low education, lack of effective warning systems etc. $[10,11]$. Although awareness of flood risk may exist, an additional issue can be lack of awareness in relation to the health implications of flooding, flood insurance cover or to weather forecasting that could increase likelihood of being prepared [10, 11, 17, 24]. 
This review established that lack of preparedness for flooding was a significant problem $[6,7,10,17,20,28,29]$. This problem was evident in both urban and rural and developing and developed countries. An additional issue was that the majority of preparation made was reactive rather than proactive $[6,10,11]$. The key reasons were lack of awareness regarding mitigation measures, lack of financial resources to invest in preventative measures, lack of 'know-how' and a limited time frame between successive flood events [5-7, 11, 13, 15, 20, 29]. Several of the studies also recognised that often residents thought they were prepared for flooding, but in reality they had not taken sufficient mitigation action or their insurance did not cover flood events [17, 23, 24]. Furthermore, some residents, despite being aware of future flood risk, chose to ignore it, believing that it would not reoccur [16]. In developed countries, homeowners and business owners are often dismissive of flood preparedness, suggesting it is entirely the government's responsibility $[17,23]$.

A key finding of this review was that the majority of flood victims who were flood prepared resided in developing countries [5, 9, 11-13, 15, 19, 21]. However, two of the studies in developed countries also illustrated flood preparedness [24, 25]. A potential explanation is that in developing countries flood victims see mitigation and preventative action as their own responsibility rather than that of government agencies, while flood victims in developed countries have a higher expectation in relation to government assistance. Additionally Mishra et al. found that place attachment significantly influenced flood preparedness, indicating that residents who had lived in the same location for generations would be more likely to take mitigation action in order to protect their heritage [28].

The review indicates that although a basic level of flood awareness did exist in all the studies, there was a lack of awareness relating to mitigation measures and the health implications of flooding. Lack of preparedness was a major issue of concern in both developed and developing countries, however, flood victims in developing countries, in both urban and rural areas were more likely to be flood prepared due to their lack of dependence on agencies. The findings of the review suggest that communities are very vulnerable to being affected by secondary stressors due to their lack of flood preparedness. It is important to raise awareness concerning the ramifications in communities if they do not prepare for flooding, emphasising that lack of awareness and preparedness for flood events can escalate the long-term impact of secondary stressors on health [10].

\subsection{Community resilience: adaptation and mitigation}

Communities are increasingly being encouraged to work together collectively to recover from and become more resilient to flooding, with little or no assistance from government agencies. Community resilience is particularly important in developing countries, where neighbours and relatives are an essential source of both emotional and physical support during flood events.

This review found significant community resilience in flood affected areas, with strong community spirit helping during the flood and making the recovery period easier $[5,7,8,10,12,17]$. It was even suggested that flooding increased community resilience, encouraging closer relationships between neighbours [8]. 
In developing countries, despite dire economic conditions almost all residents were willing to loan money and offer shelter to neighbours during flood events $[7,8]$.

It was established that both individual and community resilience was especially strong in developing countries were following flood experience as residents developed their own coping strategies to protect against flood events. The methods employed included placing barriers around houses, construction of floating houses, using concrete blocks instead of timber to reduce likelihood of floodwater entering homes and taking shelter on higher ground during flood events $[5,12]$. Farmers were found to be particularly resilient, adapting to flooding in new innovative ways, such as turning to an alternative livelihood during the flooding season or selecting crops around the timeframe of seasonal flooding [12, 13]. This is crucially important in developing countries as flooding can destroy livelihoods, however, exploring innovative ways to benefit from flooding may be something that could also be considered in developed countries.

It is important to understand that one of the key reasons as to why individual resilience often remains low is lack of financial resources. Upgrading properties as a mitigation technique to reduce flood risk allows individuals to become more resilient, however, in both developing and developed countries it is not always financially viable $[11,13,20]$. One of the key factors identified to increase the likelihood of responding to flood hazard and adapting properties was housing tenure. It was identified that owner occupier households were more likely to mitigate against flood risk through actions such as yard raising, essentially because owner occupier households tend to be a higher income group [21]. Another problem identified was that individuals took temporary short-term measures to deal with floods each year, without taking any action that will assist them during the next flood [11]. This is often due to a lack of awareness and education [12]. It is essential to improve flood education and mitigation programmes, especially within rural areas in developing countries in order to help homeowners to understand that proactive mitigation measures will reduce stress and save money in the long-term. A final problem identified was that many homeowners and businesses appeared to act alone to mitigate flood risk rather than collectively [6, 19, 20].

This review found that community resilience was higher in developing countries, both in urban and rural areas, but also in rural areas in developed countries. The development of community resilience is sometimes hampered by lack of financial resources or the use of short-term mitigation measures. It is essential to improve community resilience, particularly in urban areas in developed countries as it plays an essential role in limiting the detrimental longterm impact that secondary stressors can have on health.

\section{Conclusion}

This review concluded that both rural and urban communities in developed and developing countries are significantly affected by secondary stressors. We identified that loss of income and damage to property had an almost universal 
impact, affecting the majority of communities, despite geographical and socioeconomic differences. However, we found that other secondary stressors only impacted specific communities, for example, insurance and house prices were a significant issue in developed countries, but not in developing countries as insurance was often not available.

In relation to flood awareness and preparedness we concluded that although the majority of communities do have a basic awareness of their flood risk, many residents do not take this risk seriously and thus take little preventative action. Flood victims in developing countries, despite having fewer financial resources, were recognised as being more likely to take preventative action than residents in developed countries, due to a lesser dependence on government agencies. Developed countries must learn this lesson from the developed world, recognising that responsibility to flood proof homes does not solely lie with government institutions.

Finally, we concluded that community resilience was high in urban and rural areas in developing countries and also in rural areas in developed countries. However, we established that community resilience in urban areas in developed countries was low. A significant finding was that farmers in developing countries used innovative methods to adapt to repeated flooding. This led us to conclude that flood victims in developed countries must find their own means of adapting to repeated flood events in order to improve their coping strategies, making them more resilient and prepared for future flooding.

Future studies, which we hope to accomplish, should focus on the specific secondary stressors faced by rural and urban communities and how to minimise their impact in order to increase resilience. We concluded that different priorities exist for flood victims and it is probable that government agencies need to deal with them in different ways, even if they are located near to each other geographically. Future work could include proposing a model in relation to dealing with the long term health impacts of floods among different communities. Communities should be educated on cost effective proactive preventative measures that they can implement, allowing them to become more aware of the detrimental health impacts if only reactive action is taken. There should be a particular focus on the impact of repeated flooding in urban areas as we identified that most studies to date have concentrated on rural communities. The increasing prevalence of flooding in the developed world emphasises the need for more work in this field, thus further work will contribute to an increased knowledge and understanding of the secondary stressors that affect communities, allowing policymakers to establish if a generic approach during the recovery stage of flood events is appropriate for different communities.

\section{References}

[1] Ahern, M., Kovats, R.S., Wilkinson, P., Few, R. and Matthies, F., Global health impacts of floods: epidemiologic evidence. Epidemiologic reviews, 27 (1), pp. 36-46, 2005.

[2] World Health Organisation. Floods in the WHO European Region: Health effects and their prevention. WHO: Copenhagen, 2013. 
[3] Few, R. and Matthies, F., Flood hazards and health: responding to present and future risks, Earthscan: London, 2006.

[4] Lock, S., Rubin, G.J., Murray, V., Rogers, M.B., Amlôt, R. and Williams, R., Secondary stressors and extreme events and disasters: a systematic review of primary research from 2010-2011. PLoS currents, 4, 2012.

[5] Zahari, R.K. and Ariffin, R.N.R., Community-Based Disaster Management in Kuala Lumpur. Procedia-Social and Behavioral Sciences, 85, pp. 493$501,2013$.

[6] Hoggart, S., Hanley, M., Parker, D., Simmonds, D., Bilton, D., FilipovaMarinova, M., Franklin, E., Kotsev, I., Penning-Rowsell, E. and Rundle, S., The consequences of doing nothing: The effects of seawater flooding on coastal zones. Coastal Engineering, 87, pp. 169-182, 2014.

[7] Braun, B. and Aßheuer, T., Floods in megacity environments: vulnerability and coping strategies of slum dwellers in Dhaka/Bangladesh. Natural Hazards, 58 (2), pp. 771-787. 2011.

[8] Boon, H.J., Disaster resilience in a flood-impacted rural Australian town. Natural Hazards, 71 (1), pp. 683-701, 2014.

[9] Paul, S.K. and Routray, J.K., Flood proneness and coping strategies: the experiences of two villages in Bangladesh. Disasters, 34 (2), pp. 489-508, 2010.

[10] Tschakert, P., Sagoe, R., Ofori-Darko, G. and Codjoe, S.N., Floods in the Sahel: an analysis of anomalies, memory, and anticipatory learning. Climatic Change, 103 (3-4), pp. 471-502, 2010.

[11] Shimi, A.C., Parvin, G.A., Biswas, C. and Shaw, R., Impact and adaptation to flood: A focus on water supply, sanitation and health problems of rural community in Bangladesh. Disaster Prevention and Management, 19 (3), pp. 298-313, 2010.

[12] Mavhura, E., Manyena, S.B., Collins, A.E. and Manatsa, D., Indigenous knowledge, coping strategies and resilience to floods in Muzarabani, Zimbabwe. International Journal of Disaster Risk Reduction, 5 pp. 38-48, 2013.

[13] Nguyen, K.V. and James, H., Measuring Household Resilience to Floods: a Case Study in the Vietnamese Mekong River Delta. Ecology \& Society, 18 (3), 2013.

[14] Dun, O., Migration and displacement triggered by floods in the Mekong Delta. International Migration, 49 (1), pp. 200-223, 2011.

[15] Chhotray, V. and Few, R., Post-disaster recovery and ongoing vulnerability: ten years after the super-cyclone of 1999 in Orissa, India. Global Environmental Change, 22 (3), pp. 695-702, 2012.

[16] Kick, E.L., Fraser, J.C., Fulkerson, G.M., McKinney, L.A. and De Vries, D.H., Repetitive flood victims and acceptance of FEMA mitigation offers: an analysis with community-system policy implications. Disasters, 35 (3), pp. 510-539, 2011.

[17] Keogh, D.U., Apan, A., Mushtaq, S., King, D. and Thomas, M., Resilience, vulnerability and adaptive capacity of an inland rural town prone to flooding: 
a climate change adaptation case study of Charleville, Queensland, Australia. Natural Hazards, 59 (2), pp. 699-723, 2011.

[18] Biswas, A., Rahman, A., Mashreky, S., Rahman, F. and Dalal, K., Unintentional injuries and parental violence against children during flood: a study in rural Bangladesh. Rural \& Remote Health, 10 (1), 2010.

[19] Linnekamp, F., Koedam, A. and Baud, I., Household vulnerability to climate change: Examining perceptions of households of flood risks in Georgetown and Paramaribo. Habitat International, 35 (3), pp. 447-456, 2011.

[20] Munji, C.A., Bele, M.Y., Nkwatoh, A.F., Idinoba, M.E., Somorin, O.A. and Sonwa, D.J., Vulnerability to coastal flooding and response strategies: The case of settlements in Cameroon mangrove forests. Environmental Development, 5 pp. 54-72, 2013.

[21] Pelling, M., What determines vulnerability to floods; a case study in Georgetown, Guyana. Environment and Urbanization, 9 (1), pp. 203-226, 1997.

[22] Marino, E., The long history of environmental migration: Assessing vulnerability construction and obstacles to successful relocation in Shishmaref, Alaska. Global Environmental Change, 22 (2), pp. 374-381, 2012.

[23] Manock, I., Islam, R., Hicks, J., Sappey, R.B. and Ingham, V., Perceptions of institutional and social response to frequent flooding in an Australian rural town. Australian Journal of Emergency Management, 28 (1) pp. 42-48, 2013.

[24] Lamond, J.E., Proverbs, D. and Hammond, F., Accessibility of flood risk insurance in the UK: confusion, competition and complacency. Journal of Risk Research, 12 (6), pp. 825-841, 2009.

[25] Laska, S.B., Homeowner Adaptation to Flooding an Application of the General Hazards Coping Theory. Environment and Behavior, 22 (3), pp. 320-357, 1990.

[26] Rodriguez-Llanes, J.M., Ranjan-Dash, S., Degomme, O., Mukhopadhyay, A. and Guha-Sapir, D., Child malnutrition and recurrent flooding in rural eastern India: a community-based survey. BMJ open, 1 (2), 2011.

[27] Wind, T.R., Joshi, P.C., Kleber, R.J. and Komproe, I.H., The impact of recurrent disasters on mental health: a study on seasonal floods in northern India. Prehospital and Disaster Medicine, 28 (03), pp. 279-285, 2013.

[28] Mishra, S., Mazumdar, S. and Suar, D., Place attachment and flood preparedness. Journal of Environmental Psychology, 30 (2), pp. 187-197, 2010.

[29] Mattei, N., Stack, S., Faris, M., Adeinat, I. and Laska, S., Mitigation of repetitively flooded homes in New Orleans, Louisiana. Ecosystems and Sustainable Development VII, 122 pp. 365-378, 2009. 